\title{
Research on Industry-University-Research Cooperative Education of Local Normal Universities in China from the Perspective of Teaching Assessment
}

\author{
Xuhong Wang \\ Department Office of Educational Administration, Chengdu Normal University, Chengdu, China \\ Email:706975889@qq.com
}

How to cite this paper: Wang, X.H. (2019) Research on Industry-University-Research Cooperative Education of Local Normal Universities in China from the Perspective of Teaching Assessment. Open Access Library Journal, 6: e5361.

https://doi.org/10.4236/oalib.1105361

Received: March 28, 2019

Accepted: April 20, 2019

Published: April 23, 2019

Copyright $\odot 2019$ by author(s) and Open Access Library Inc.

This work is licensed under the Creative

Commons Attribution International

License (CC BY 4.0).

http://creativecommons.org/licenses/by/4.0/

(c) (i) Open Access

\begin{abstract}
Cooperative education is very important in the innovation-oriented national construction. It is an effective way to improve quality of teaching by cooperative education of industry, university and research, which plays critical role in cultivating undergraduates' practical and innovative ability. This paper analyzes the current situation of cooperative education in local normal universities from the perspective of qualification assessment. The internal and external factors that influence the depth of cooperative education are discussed. Some specific advices are put forward from the aspects of renewing understanding, playing the leading role of governments at all levels and improving cooperation mechanism.
\end{abstract}

\section{Subject Areas}

Education

\section{Keywords}

Local Normal University, Industry-University-Research Cooperative

Education, Teaching Assessment

\section{Introduction}

In the index system of undergraduate teaching qualification assessment, the Ministry of Education requires universities cooperating with enterprises and research institution to construct specialties, teaching resources, train talents and promote employment. 
The cooperative education of industry, university and research institution is an effective model in higher education, in which teaching, practice, science and technology research can be integrated by making full use of the educational resources and environment of the university and society. During the cooperation, these are important: the training mode for innovative talents, practice teaching, the environment for practice. It plays a unique role in cultivating college students' innovation ability and plays an important role in the construction of an innovation-oriented country [1]. One of the purposes of teaching qualification assessment is to guide newly-built universities to carry out industry-university-research cooperative education actively.

Industry-university-research cooperation contains two meanings: cooperative innovation and cooperative education. In this paper, we focus on discussion about deep cooperative education. In recent years, driven by qualification assessment, new universities have set off a new upsurge in the practice of industry-university-research cooperation and a number of successful examples of cooperative education have emerged. The cooperative education is well developed in higher vocational colleges, such as Ningbo Polytechnic Shenzhen Polytechnic and Henan Mechanical and Electrical Engineering College. The teaching and research personnel have made a large number of empirical studies on industry-university-research cooperative education. In their study, some effective measures were summed up and a variety of educational modes were put forward, which enriched the research and practice of our country. Five modes of industry-learning cooperative education in higher vocational colleges have been mentioned (Zhu Haiyue, 2012). But on the whole, the industry-university-research cooperative education in newly-built universities is still in the primary stage of exploration. Chengdu Normal University experienced teaching qualification assessment in 2018. This paper takes Chengdu Normal University as example. The author is responsible for the projects management, and conducted deep interviews with more than 30 project leaders.

\section{Status Analysis}

\subsection{Form and Content Need to Be Enriched}

Although the number of cooperative education programs has increased every year, the number is limited and the development is uneven.

In recent years, the Ministry of Education called on domestic enterprises and units to join in the programmes to promote collaborative education and professional comprehensive reform of universities. There is a statistical table about the industry-university cooperative education project in Chengdu Normal University. From Table 1, data shows the cooperation projects are increasing year by year. Chengdu Normal University encourages teachers to apply and promises to offer $¥ 30,000$ for each project construction. It can be seen from this trend that the enthusiasm of teachers' participation has been improved. It also shows that universities are paying more attention to this work. From the platform cooperation and collaborative education of the ministry of education, we know that the 
Table 1. The project statistics (Chengdu Normal University participated in the collaborative education projects held by the Ministry of Education) [2].

\begin{tabular}{cccc}
\hline Year & 2016 & 2017 & 2018 \\
Item type & 4 & 12 & 19 \\
Teacher training & 1 & 4 & 11 \\
Reform of teaching content and curriculum & 0 & 7 & 7 \\
Practice condition and base construction & 0 & 6 & 3 \\
Innovation and entrepreneurship education reform & 0 & 0 & 1 \\
Joint fund for innovation and entrepreneurship & 0 & 0 & 0 \\
\hline
\end{tabular}

number of enterprises participating in the cooperation is increasing year by year. This change indicates that the overall cooperative environment has been improved. However, there are still gaps in terms of project types.

\subsection{The Depth and Breadth Is Not Enough}

Local normal universities have carried out various forms of cooperative education. They jointly build the off-campus base for practice, jointly discuss the professional training program, and jointly discuss the teaching content of some professional courses. On the whole, the content of cooperation is not diversified enough, and the teaching resources jointly built by the cooperation are not rich enough. The cooperation with the industry focuses on the reform of curriculum system, teacher training and solving student internship. The ways and means of bilateral cooperation are still relatively simple. For enterprises, cooperation means to occupy the big market of universities and promote the use of their own technological achievements. In the cooperation, the university is more like a test field and buyer. Usually, these projects issued in the Ministry of Education require to be completed within one year. The enterprises provide certain fund and platform support for the university, they are not involved in the implementation. On one hand, it was for lack of substantive exchanges and research platforms. On the other hand, universities attach importance to project application but not to process management. In Chengdu Normal University, some teachers are in charge of 2 or 3 different projects at the same time. For the project leaders, project completion is more important than improvement. Successful experience at home and abroad shows that great gains can't be achieved without long-term and deep integration.

In Table 2, Sichuan Normal University and Chengdu Normal University lie in Chengdu, the provincial capital of Sichuan, China West Normal University lie in Nanchong which is a big city with developed economy. The other four with long history of normal education are in small cities. According to the data in Table 2, the local normal universities in big cities got more cooperative projects, while those in remote areas had few chances. That is to say, the enterprises are more 
Table 2. The project statistics of local normal universities in Sichuan province in west China [2].

\begin{tabular}{ccc}
\hline The amount in a year & 2017 & 2018 \\
Normal university & 23 & 35 \\
\hline Sichuan Normal University & 29 & 41 \\
Chengdu Normal University & 20 & 40 \\
China West Normal University & 11 & 10 \\
Mianyang Normal University & 4 & 3 \\
Neijiang Normal University & 6 & 13 \\
Leshan Normal University & 4 & 3 \\
Aba Teachers University & & 3 \\
\hline
\end{tabular}

willing to cooperate with universities in economically developed central cities.

\subsection{The Effect of Cooperative Education Is Not Ideal}

With the transformation and upgrading of local economy, local normal universities have embarked on the road of transformation and development. Dependent on local economic construction and regional advantages, some non-normal majors have been set up. Because of the history and tradition of normal universities, the cooperation with primary and secondary schools and kindergartens has a good foundation and advantages, while the collaboration with the enterprise is quite difficult. Due to short time, the new majors are not accurate on orientation, and professional characteristics are not outstanding. There are few achievements in teaching and scientific research, and few achievements have been transformed into productivity. Among these cooperations, there is no large or famous enterprise. Universities and cooperative enterprises have signed agreements, but the level is not high. Constructing practice base is the main mode of industry-university-research cooperation. This mode does not require universities to invest a large amount of capital in the construction, and solves the problem of student internship places. Students can be familiar with the work process and routine methods in the simulation environment, but the cultivation of students' innovative thinking is quite limited [3]. In the process of cooperative education, the arrangement of professional curriculum system is not closely connected with the needs of industry. Practical instruction is not well carried out without detailed requirements in the management. In such cooperation, there is a big gap to realize cooperative education and development. To the normal university, the social resources to be exploited are limited. Particularly, the cooperative education of non-normal majors is still in the exploratory stage. Therefore, it is difficult for local normal universities to cultivate the innovative ability of application-oriented talents. Visible changes and invisible changes are brought through cooperative education. On the whole, it has no obvious effect on improving teaching. According to the feedback from most graduates, the promotion of students' study and growth has not been proved. After all, the history of 
cooperative education in local normal university is too short. The current accumulation is not enough to make a big difference.

\section{Reason Analysis}

The breadth and depth of cooperative education depend on subjective attitude and objective environment.

\subsection{Internal Factors}

In the transformation development, the limitations of local normal universities impede the process of cooperation. There is a deviation in the understanding of industry-university-research cooperation. Most of the newly-built universities are upgraded from higher vocational college or adult colleges. Chengdu Normal University is from adult college after its comprehensive reform. Influenced by former educational mode, the staff in local normal universities has no clear perception about industry-university-research cooperation. One of the most unusual findings in the study was the fact that for some teachers, the cooperation had no meaning at all. They could not define it nor did they know what it was. Most teachers believed it was none of their business. In their mind, only the educational internship could be involved in cooperative education. To some leaders, the sense of open education and serving the local economic is not urgent, let alone the cooperation with others. As a result, their knowledge of the curriculum is not correspond to reality or fall behind current technology. Without advancing thinking, it is difficult to promote professional reform and the contribution of the curriculum could not be achieved effectively.

In local normal university, the hardware and software are inadequate; the teaching force is still weak; the ability to serve the regional economy is not strong enough. The local normal university depends on local government financial allocation. In view of the characteristics of application-oriented personnel training, the insufficient fund and limited resources become more prominent. To build these applied majors well, corresponding practice and training bases are needed on one hand; double professional teachers are urgently needed on the other hand. Both of them require a large amount of capital input, which cannot be solved in a short time by the university. Nowadays, although the local normal universities are raising funds from many ways and the conditions are constantly improved, there are still many deficiencies. Such local normal universities are still in the late stage of transformation and development after many years of upgrading. The university added applied majors and has adjusted the existing majors. In fact, after the adjustment, there still is something unreasonable. Different disciplines belong to the same college. It is not conducive to professional construction and professional development of teachers. Due to the short history of undergraduate education, long-term education is dominated by teacher education; the social adaptability and recognition of application-oriented majors are not high. In these newly transformed local normal universities, most of the 
teachers have master degrees or above, and the younger staff have no practical learning in enterprises or lack of communication with relevant industrial. As for the university administration, there was no an effective mechanism to introduce talents from enterprises. The lack of academic leaders and dual-ability teachers seriously restricts the development of industry-university-research cooperative education. Under such circumstances, the universities pay more attention to the scientific research. For a long time, the research foundation is weak. That is to say, the university is too weak in scientific research to provide high quality technology services. In the university, management lacks effective rules and regulations to encourage teachers to participate in cooperative education, which lead to insufficient experience in cooperative education.

\subsection{External Factors}

Compared with key universities or undergraduate universities with long history, the software and hardware facilities of local normal universities are inferior. These universities have no voice in the cooperative programmes. There are even few opportunities for collaboration. The most important reason is that the communication channels are not smooth and effective collaboration mechanisms are imperfect [4]. After experiencing merging and restructuring, these newly-built universities are not known by the people. Local government support for such university is also far from enough. At present, the government has issued few incentive policies to promote industry-university-research cooperation. Although our government proposes to encourage industry-university-research cooperative education in the Outline of the Thirteenth Five-Year Plan of China, the rights and obligations of the subjects participating in the cooperation are not stated clearly. The law of industry-university-research cooperative education suggested by Li Guimin has not yet been formulated. Clear policies and regulations are crucial to the breadth and depth of cooperation. In the era of network, the entity economy faces enormous pressure and challenges in development. It is also unrealistic to expect enterprises to invest a lot of energy, resources and fund in the process of cooperation. For enterprises, if they cannot get corresponding benefits from the cooperative education projects, then the cooperation is only temporary and superficial. From the perspective of evaluation index system, educational administrative departments have vague requirements for cooperative education, and no corresponding evaluation system can be used to judge the result effectively.

Enterprises are not active in cooperative education. Firstly, it is a kind of social responsibility for enterprises and entrepreneurs to support talents cultivation and education [5]. But not all enterprises have the capacity, not all entrepreneurs have the awareness, especially those small and micro enterprises in the initial stage. Although they are more eager to get technical and personnel support from universities and research institutes, cooperative education is bound to affect the economic benefits of enterprises for some time. Therefore, the corpo- 
rate principal's sense and attitude to social responsibility are decisive factors for the effective cooperation. Secondly, cost-benefit analysis is the most important factor that affects enterprises' participation in cooperative education [6]. The goals and tasks of both bilateral are different. There are inevitable contradictions: the contradiction between teaching task and production task, the contradiction between teaching process and production process [7]. After all, to cultivate students' application ability, local normal universities need to borrow devices and technical guidance from enterprises by cooperation, while return to enterprises is very small in short term. From this viewpoint, the cost of cooperative training is too high, or the profit of enterprises cannot compensate the cost of talent training.

\section{Suggestions}

\subsection{Perspectives on the Value of the Cooperation}

Under the circumstances of innovation, both local normal university and enterprises should realize that industry-university-research cooperative education is not only the requirement of the times, but also a good opportunity for their own development.

Industry-university-research cooperative education has brought about great changes and influences to local normal universities. Namely, it has changed the conditions of university, changed the mode of teaching and learning, changed teachers and students. Cooperation has influence on the campus culture and the social reputation of the university to some extent [4]. Cooperative education can effectively improve the training conditions, which is the foundation of improving the quality of practical teaching and the cultivation of innovative talents. In the cooperative education, teachers must transform themselves into dual-qualified teachers. They should not only learn new knowledge, but also pay attention to the industry technology frontier. Facing these new reformations, teachers have to reflect and deal with these changes. For students, their practical skills are well consolidated, good professional quality is trained; the social adaptability is improved. All these created favorable conditions for the employment in the future. Strict discipline, team spirit and professional dedication in working have a great impact on campus culture. The permeating of campus academic culture and enterprise culture can contribute to cultivate students' professional spirit [8]. Enterprises' acceptance and recognition of undergraduates is a benchmark to measure the quality of teaching, which has great influence on university's social reputation.

For enterprises, the in-depth industry-university-research cooperative education will benefit the enterprise in the long term. From the viewpoint of development, the person in charge of the enterprise should not only consider the short-term economic interests of the enterprise. The leaders must realize that carrying out industry-university-research cooperative education is to develop the enterprise better. Teaching facilities and faculty provide effective support for 
enterprises to train employees and improve their cultural literacy. As a center of knowledge, university could put forward good suggestions for the development of enterprises. Enterprises' reputations are growing by close cooperation with university. The deep cooperation could stimulate the new vitality of the staff and enrich and enhance the connotation of enterprise culture.

\subsection{Efforts at Local Normal University's Level}

Local normal universities should take great efforts to enhance their comprehensive strength constantly, improve the mechanism, and pave the way for industry-university-research cooperative education

Firstly, university leaders must change their mind and seek cooperation opportunities initiatively.

Zhang Daliang, director of the Education Department, believes that industry-university-research cooperative education is an important platform and mode of talent cultivation, which must be adopted in cultivating application-oriented talents and is very important in academic talent training [4]. Industry-university-research cooperative education has developed in China for more than 20 years and played an active role in the cultivation of talents in higher education. The whole process of talent training is no longer close and one-way. According to the orientation of local normal university and the needs of society, student must perceive and test knowledge in practice. So the leaders in local normal university should be aware that cooperative education is an effective way for cultivating high-quality applied talents and the successful transformation and long-term development of the university.

Secondly, we should establish and gradually improve the system of industry-university-research cooperative education. University, as the main body of cooperative education, should deepen and promote the reform from the following three aspects. The first is to strengthen the organization and leadership. To set up cooperation institutions, clarify the short-term and long-term goals of cooperation after deep research and analysis. The second is to connect with local governments and their administrative departments closely. Establish a win-win mechanism between university and industry enterprises timely. The third is to strive for policy and financial support from government and industry. It is necessary to increase funding for industry-university-research cooperative education, and continue to promote the positive interaction.

Thirdly, we should guide teachers to change their ideas and take measures to promote industry-university-research cooperation as a whole. Emotions, past experiences, ideologies, teaching styles and sense-making appear to be important determinants of teachers' behavior in reforms. It is very helpful to promote the reform by rooting this new idea among teachers. After all, it depends on teachers to fulfil. To realize all-round cooperation, it is crucial to break through the limitations of cooperation, strengthen the depth and breadth of integration. By broadening horizon and channel, the reforms make room for university man- 
agement, the construction of staff, the construction of majors and curriculums, practice training, teaching evaluation, research and other fields.

Fourthly, local normal university should attach importance to the cooperation, communication and coordination with small and medium-sized enterprises, and take the initiative to serve the local government. By making full use of the media, let the outside know more about such university. In particular, the university demonstrates its achievements and characteristics. Actively put forward suggestions for local economic construction and social development. To meet the local needs of application-oriented talents, we should carry out on-the-job training and fixed-point training to enhance the pertinence of talent training.

Fifthly, to strengthen the teaching staff by training and introduction. We can do this in the following ways. Local normal universities are also application-oriented universities. The number of application-oriented research and its transformation is important to cooperative education. The first is to build high-level scientific research teams, in which the exemplary role of outstanding talents and collective efficacy may be able to increase. The second is to grant more honors and awards to those technological achievement transformations on one hand, and try to expand the use of achievements on the other hand. Scientific research achievements are directly converted into real productivity, which attract the enterprises to participate cooperative education. The third is to make full use of the policies of local governments. At the background of cooperative education, a full range of effective measures should be taken to guide university teachers to carry out field investigation and research in enterprises, and invite enterprise engineers as honorary professors to guide the practical teaching at the same time.

\subsection{Perceptions of the Role of Government}

After investigating the present situation of cooperative education in developed country's higher education, we can find that the state's institutional protection is essential, in addition to the sense of responsibility and social morality of entrepreneurs. Higher education has increasingly become the foundation of the country's sustainable economic growth and harmonious social development. Industry-university-research cooperative education is an important strategy in modern education mode. In quite a long time, governments at all levels must think about how to develop cooperative education and take effective measures. At the national level, perfect legal basis and guarantee is necessary to realize the systematization and institutionalization of industry-university-research cooperative education. At present, it is a common practice for local governments to reduce corporate taxes and costs, but more efforts are needed. At the same time, local governments should also increase financial support for local normal universities and policy support for small and micro enterprises. Act as a bridge, local governments are responsible for coordinating the relationship between the education, technology and other sectors, and fostering good models of coopera- 
tion [3]. The cooperative platform (e.g. cxhz.hep.com.cn) has been built, but there is no relevant evaluation authority. To develop the cooperative education better, it is necessary to introduce third-party evaluation agencies to track the implementation and completion of both sides. At the level of education authority, the evaluation system of the effect should be further improved. As a result, the local normal university regards the cooperative education as an important part of the quality assurance system, both sides take cooperative education seriously rather than superficially. The government should publicize the effective cooperative education widely. Good examples could provide experience and reference for others, which promote the development of cooperative education comprehensively [9]. The government is not only a leader, but also a matchmaker and a supervisor in the cooperative education.

\section{Conclusion}

Government enterprises and universities are the three elements of knowledge economy society. Government is the guarantee of steady contract and it is in the leading position of cooperative relationship. Universities, the sources of new knowledge and technology, provide human intelligence support, and enterprises are the places of technological innovation. The collaborative process is still full of difficulties and challenges even in the sound situation [10]. In sum, interaction and win-win is the common direction of local governments, universities and enterprises. The purpose of teaching assessment is not only to check result. Instead, it is more than to promote construction, management and reformation. However, much remains to be done. In China, the economic efficiency is always put in the first place. Little consideration is given to the needs of students. In this paper, the role of students in promoting cooperative education was not discussed. Students are the biggest beneficiaries. The needs of students reflect the needs of society. So to form a virtuous circle mechanism, the needs of students should be valued in the future cooperative education. The establishment of professional evaluation institution and evaluation criteria will be helpful to perfect the operational mechanism of cooperative education. It is a complicated process to evaluate cooperative education fairly and objectively.

\section{Conflicts of Interest}

The author declares no conflicts of interest regarding the publication of this paper.

\section{References}

[1] Ma, Y.F. and Xu, M.J. (2018) Industry-University-Research Cooperation Promotes the Cultivation of Innovative Talents. Cultural and Educational Information, No. $17,123-124$.

[2] A Letter On announcing the List of Industry-University Collaborative Education Projects from the Higher Education Department of the Ministry of Education. 
http://cxhz.hep.com.cn/detail_notice.html?NoticeID=df01aa88-9b85-4897-8bbe-d1 025a10ed3

[3] Peng, F. (2016) Industry-University-Research Cooperative Education and Cultivation of Innovative and Entrepreneurial Talents: A Case Study of Warwick University[J]. Journal of Higher Education, No. 3, 25-27.

[4] Jiang, J.L. (2017) Exploration on the Cultivation Path of College Students' Innovation Ability from the Perspective of Industry-University-Research Integration. Journal of Higher Education, No. 20, 26-28.

[5] Wu, Y. (2010) New Concept, New Goal and New Task of China's Industry-University-Research Cooperative Education Development. Beijing Education, No. 1, 5-9.

[6] Wu, Y. (2007) Research and Reflection on Industry-University-Research Cooperative Education in Higher Vocational Colleges in China. Hebei Normal University, Hebei, 43-48.

[7] Wei, W.L. (2017) Cooperative Education of Application-Oriented Universities in the New Normal. Journal of Anhui Agricultural University (Social Science Edition), No. 3, 102-108.

[8] Pan, Y.Y. (2008) Several Theoretical Problems of Industry-University-Research Cooperative Education. China University Teaching, No. 3, 15-17.

[9] Sun, J. (2011) The Current Situation, Problems and Countermeasures of Production-Study-Research Cooperative Education in Local Universities in Guangdong Province. Chinese Higher Education, No. 4, 58-61.

[10] Liu, Z.H. (2015) The Embodied Value and Implementation Strategy of the Education of Industry-University-Institute Cooperation in New Universities. Theory and Practice of Education, No. 33, 9-11. 